\title{
Market Expectations And Probability Distributions Implicit In Option Prices
}

Michael McIntyre, (E-mail: mmcintyr@sprott.carleton.ca), Carleton University Miwako Nitani, (E-mail: mnitani@connect.carleton.ca), Carleton University

\begin{abstract}
This paper investigates whether specific characteristics of the returns distributions implied by options prices constitute useful information for the purpose of predicting changes in market direction. The key distributional characteristics we focus on are skewness, kurtosis, and the probability weight in the extreme tails of the implied distributions. We present a new methodology for extracting the returns distributions and apply it to $S \& P 500$ index futures-options prices for twenty days surrounding the four largest market reversals in calendar 2001.
\end{abstract}

\section{Introduction}

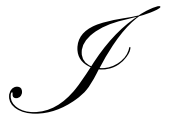

n modern theoretical option pricing models, option prices are discounted expectations of future outcomes for the underlying. To the extent that transaction prices for options follow option-pricing theory, option prices are expressions of the market's aggregate expectations. Thus, an instantaneous set of prices of call and/or put options with the same underlying asset and maturity across a wide range of strike prices gives a very direct indication of market participants' aggregate view of outcomes for the underlying on that maturity date. For example, if the prices of deep out-of-the-money ("OTM") put options are relatively large compared to deep OTM call options, this may imply that the market is placing more probability weight on a downward movement in the price of the underlying than on an upward movement. Conversely, prices of OTM calls that are relatively high compared to OTM puts could be interpreted as an indication that the market expects an upward movement in the price of the underlying.

Bates (1991) examined the S\&P 500 index futures option prices for evidence of expectations of the market crash in October 1987. The market showed the following movement prior to the crash: from October 1986 to August 1987, the market experienced a $42 \%$ upsurge, reaching its peak on the $27^{\text {th }}$ of August. After the peak it exhibited a gradual decline with fluctuations until the crash. Bates found that OTM put options on S\&P 500 futures traded unusually higher than OTM calls during the period of the market upsurge. This manifestation of "an expectation (or fear) of a market crash" became pronounced in July and August of 1987, subsided near the market's peak in late August, and disappeared with the market's decline until the crash. These observations led Bates to argue that the October 1987 crash was expected, notwithstanding that the expectation appeared to manifest itself two months prior to the occurrence of the crash.

Two possible lines of inquiry present themselves. The first is that option prices may contain information about future market moves that can be extracted and exploited by trading strategies. The second is that market fluctuations may be an artifact of market participants' sentiments after the occurrence of a sustained upward or downward move in the market. The line of reasoning with respect to this latter issue is as follows. If Bates' finding is characteristic not just of the period 1986-1987, but of stock markets in general, then accumulations of market moves in one direction arguably carry with them a decreasing expectation among market participants of a continuation of the trend, and an increasing expectation of a reversal. This raises the possibility that market fluctuations are a result of self-fulfilling prophecies in the sense that they are caused by trading strategies that are motivated by the expectation of a reversal rather than by a change in market fundamentals or firm specific fundamentals. In other words, market movements themselves generate fluctuating expectations, which in turn generate market fluctuations. 
This study investigates the relationship between market expectations and subsequent market reversals. Specifically, it investigates market expectations implied by call option prices on the days immediately before changes in market trends, and examines whether changes in expectations coincide with realized reversals in trends. If expectations impounded in option prices represent a useful processing of information by market participants, or if market fluctuations are driven to a material extent by market sentiments as reflected in option prices, then one should find in option prices the expectation of a downturn before the occurrence of a downturn, and the expectation of an upturn before the occurrence of an upturn.

Like Bates', this study estimates market expectations using probability distributions implicit in S\&P 500 index futures option prices. Unlike Bates', who retrieves probability distributions using a model for pricing options with a jump diffusion process, we used a state-claim-pricing approach ${ }^{1}$ to recover the market participants' aggregate probability density functions of S\&P 500 futures prices.

This paper is organized as follows. The next section presents a brief literature review and theoretical development. Nest we present our methodology, and describe the data we use in this study. Finally, we present the results and conclude.

\section{Literature Review and Theoretical Development}

The development of option pricing theory and the fact that, for some underlyings (e.g. market indices), a wide range of strike prices and maturities are traded enable us to use observed option prices to specify the returns distributions that ostensibly motivate the option prices. One can argue that these returns distributions reflect the market's expectations concerning future outcomes for the underlying. Without our current level of understanding of option prices and the rich set of data that is available from well-organized public option markets, accurate estimation of market expectations would be very difficult. For example, Shiller (1989) used a survey method to look for evidence of expectations of the October 1987 crash. Most individual and institutional respondents said they had thought prior to the crash that the market was overpriced, however Shiller's methodology makes these results vulnerable to the criticism that they were biased by hindsight.

One well-known metric for quantifying market expectations is the Black-Scholes (1973) implied volatility curve. In this context, implied volatility is the volatility value that, when used in the Black-Scholes option pricing expression together with the rest of the model's parameters, returns the desired option price. The implied volatility curve is a plot of Black-Scholes implied volatility against strike price for a set of options on a common underlying and with a common maturity date, but with different strike prices. If observed option prices were to adhere perfectly to the assumptions in the Black-Scholes model the implied volatility curve would be constant across strike prices. In practice either (or both) tails of the curve can be upward sloping or downward sloping. The curve is sometimes called the "volatility smile". The extent to which the implied volatility curve deviates from the flat curve implied by the Black-Scholes model is sometimes used as a measure of the extent to which probability mass in the tails of the returns distribution deviates from the normal density function. Disproportionate mass in the right tail can be construed as a market expectation of an upturn in the underlying and disproportionate mass in the left tail can be construed as a market expectation of a downturn. ${ }^{2}$

One can also examine the condition of market expectations by comparing of the price of an out-of-themoney ("OTM") European style put option to the price of an OTM European style call option, where both options are written on the same underlying and have the same maturity date. The approach argues that OTM put options reflect conditions in the lower tail of the risk-neutral distribution of the underlying asset price, and OTM call options reflect conditions in the upper tail. Comparison of the put price to the call price, where the strike prices of each are spaced symmetrically around $\mathrm{E}\left(S_{T}\right)$ under the risk-neutral measure, provides information concerning the symmetry or asymmetry of the risk-neutral distribution. The distribution is symmetric when OTM puts and calls are equally priced. It is negatively skewed when OTM put prices exceed OTM call prices, suggesting that the market expects a downturn in the price of the underlying asset. It is positively skewed when OTM call prices exceed OTM put prices, suggesting that the market expects an upturn in the price of the underlying asset. 
Bates (1991) uses a comparison of OTM puts to OTM calls to test the hypothesis that the October 1987 crash was expected. Using transaction prices of S\&P 500 futures options over the period 1985-1987, he measured skewness premia - the percentage deviation of $x \%$ OTM call prices from $x \%$ OTM put prices. He found that starting late in 1986, the market's strong assessment of downside risk (negative skewness premia) began emerging as stock prices started to soar in July and August 1987 reaching their the peak on the $27^{\text {th }}$ of August. Bates found that in the first week of August 1987, 4\% OTM puts were about 25\% more expensive than corresponding OTM calls. After that, negative skewness premia subsided as stock prices reached their peak and disappeared when stock prices began to decline after August $27^{\text {th }}$.

Bates also fitted a jump-diffusion model to daily options prices during 1987 and retrieved the market's subjective probability density functions of S\&P 500 futures implicit in call and put options on the futures. Negative skewness emerged in implicit distributions in October 1986, as stock prices started increasing. Negative skewness became most pronounced in June-August 1987, concurrent with stock prices approaching their peak, and subsided markedly when the prices hit their peak and started decline. Moreover, expected negative jumps per year implicit in prices of a primitive security that pays off $\$ 1$ in the event of a jump occurring within the interval $(t, t+\Delta t]$ and $\$ 0$ otherwise highlighted that crash fears became strongest as the stock prices were reaching their peak. These observations led him to hypothesize that the US stock market crashed in October 1987 because it was expected to crash: the crash was a self-fulfilling prophecy - a "rational bubble".

Following the Bates's study, Rappoport and White (1994) examined whether the crash of 1929 was expected. Although there were no well-organized options markets in the 1920's, there was a very active market in brokers' loans collateralized by stock. Rappoport and White cast brokers' loans as options written by lenders and bought by borrowers, and investigated market expectations using those pseudo-options prices. Unlike Bates, who retrieved implied probability distributions and measured "a fear of crash" through skewness, Rappoport and White assessed the crash fear through return volatilities implied by the options (loans) prices calculated using the BlackScholes and the knockout option pricing models. They found that implied volatilities rose sharply coinciding with the stock market boom (before the crash). In addition, the interest premia and the margin demanded on the brokerage loans rose sharply during the stock market boom and returned to their pre-1929 levels immediately after the crash.

In 1929, stock prices had continued to soar until immediately before the crash. Rappoport and White found that the fear of a crash grew up to the moment of the crash. Bates found that in 1987 stock prices peaked two months before the crash. After the peak, prices started to decline and then the crash occurred. Bates found that the fear of a crash grew until one week before stock prices peaked and then the fear subsided during the week before the peak and disappeared when prices started to decline. These two results are consistent in the sense that an increase in the market's expectation of a downward movement in stock prices arose coincident with an up-surge in stock prices, and decreased or disappeared coincident with a decline in stock prices. The studies are inconsistent, however, in the sense that the timing of the development and dissipation of crash fears differed markedly. This inconsistency leads us to question which pattern might exist in today's markets. In addition, the question arises as to whether or not the evolution of the magnitude of crash fears can be tracked and used to predict changes in market direction for changes other than just negative changes, and for changes that are less dramatic than the 1929, and 1987 crashes. Also, unlike Bates' study that used an option-pricing model with a jump diffusion process to retrieve implicit probability distributions, this study uses a state claim pricing approach. Whereas Bates' study assumes that the stock prices follow a jump-diffusion process, this study makes no assumption concerning the stochastic evolution of asset prices beyond that implied by the assumption that call options are be priced as the discounted expectation:

$$
C(t)=B(t, T) \mathrm{E}_{t}^{Q}[S(T)-K \mid S(T)>K]
$$

In (1), $C(t)$ is call option price, $B(t, T)$ is the price of a zero-coupon riskless bond at time $t$ that pays one dollar at time $T, \mathrm{E}_{t}^{Q}$ denotes an expectation operator under the risk neutral measure at time $t, S(T)$ is asset price at time $T$, and $K$ is the strike price specified in the option contract. Following arguments analogous to those made in 
Breeden and Litzenberber (1978), we define $\varphi(S(T))$ as the density function of $S(T)$ conditional on $S(t)$ under the measure $Q$, and restate (1) as follows:

$C(t)=B(t, T) \int_{K}^{\infty}(S(T)-K) \varphi(S(T)) d S(T)$.

Differentiating (2) twice with respect to $K$ gives:

$$
\frac{\partial^{2} C}{\partial K^{2}}=\left.B(t, T) \varphi(S(T))\right|_{S(T)=K}
$$

In other words, the second derivative of option price with respect to strike price returns the probability density function of asset price on a present value basis. Dividing both sides by $B(t, T)$ we obtain the following expression for the density function:

$$
\varphi\left(\left.S(T)\right|_{S(T)=K}=\frac{\partial^{2} C}{\partial K^{2}} B(t, T)^{-1}\right.
$$

We implement (4) in the same manner as in Breeden and Litzenberger (1978) using a numerical second derivative with respect to strike price:

$$
\frac{\partial^{2} C}{\partial K^{2}} \cong \frac{[c(X+\Delta X, T)-c(X, T)]-[c(X, T)-c(X-\Delta X, T)]}{(\Delta X)^{2}}
$$

Defining $B(t, T) \equiv e^{r(T-t)}$, and,

$c^{\prime \prime}(X, T, \Delta X) \equiv \frac{[c(X+\Delta X, T)-c(X, T)]-[c(X, T)-c(X-\Delta X, T)]}{(\Delta X)^{2}}$

and letting $X_{i+1}=X+\Delta X, X_{i}=X$, and $X_{i-1}=X-\Delta X$, then:

$$
P_{i}(X) \approx e^{r(T-t)} c^{\prime \prime}(X, T, \Delta X)
$$

We provide details of our process for implementing this approach in the following section.

Shimko (1991) and Neave and Ross (2001) also use Breeden and Litzenberger's approach to obtaining probability density functions from option prices. Shimko recovered probability distributions of OEX index values implied by OEX index call option prices for the period January 1987 to December 1989. To obtain option prices sufficiently closely spaced in the strike price dimension to take useful numerical second derivatives, Shimko inverted the observed option prices into strike-price/implied volatility space and regressed the implied volatilities against strike prices and their squares to estimate a functional expression for the implied volatilities. He then used the estimated functional expression for volatility to fill in gaps in the option price observations. While this study adopts this general approach, it was our view that Shimko's second order polynomial for implied volatility did not fit sufficiently well to the observed implied volatilities. For this reason, this study uses a Hermite polynomial to model the functional form of the implied volatilities. 
Shimko's study examined information contained in the retrieved probability distributions. He found that lagged changes in the mean of the implied distribution could be used to predict future changes in the index value. Moreover, he found that changes in the mean of the implied distribution co-varied closely with changes in the underlying index value, and that the mean of the implied distribution was significantly negatively correlated with the volatility of the distribution. This suggests that volatility tends to drop when the index rises.

Similar findings were obtained in Neave and Ross. Neave and Ross retrieved implied probability distributions for four specific days using observations for call options on S\&P 500 index futures for the period January 1 to May 31, 2000. They found that the variances of the implied distributions were largest when the means of the distributions were low, and the variances were smallest when the means were high.

This study seeks to retrieve probability density functions from option prices for the purpose of examining the key properties of the density functions (mean, variance, skewness, and kurtosis). In addition, we propose to examine the behaviour of the probability density assigned by the market to the tails of the density functions dependent on whether a market downturn or upturn is imminent, or has just occurred.

\section{Methodology}

We selected four dates on which local extrema occurred by inspection of the graph of S\&P 500 index levels for calendar 2001. Although it would be desirable to include more "events" in the study, we limited the selection to four due to resource constraints. ${ }^{3}$ We elected to examine two "market highs", which occurred on January 30 and May 21, and two "market-lows", which occurred on April 4 and September 24. We also included September 10, 2001 to obtain a reading of the market on the day before the World Trade Center tragedy. The graph of S\&P 500 index levels in Figure 1 depicts the days we selected and the movements in the index level around those dates.

Figure 1

S\&P 500 Index Levels

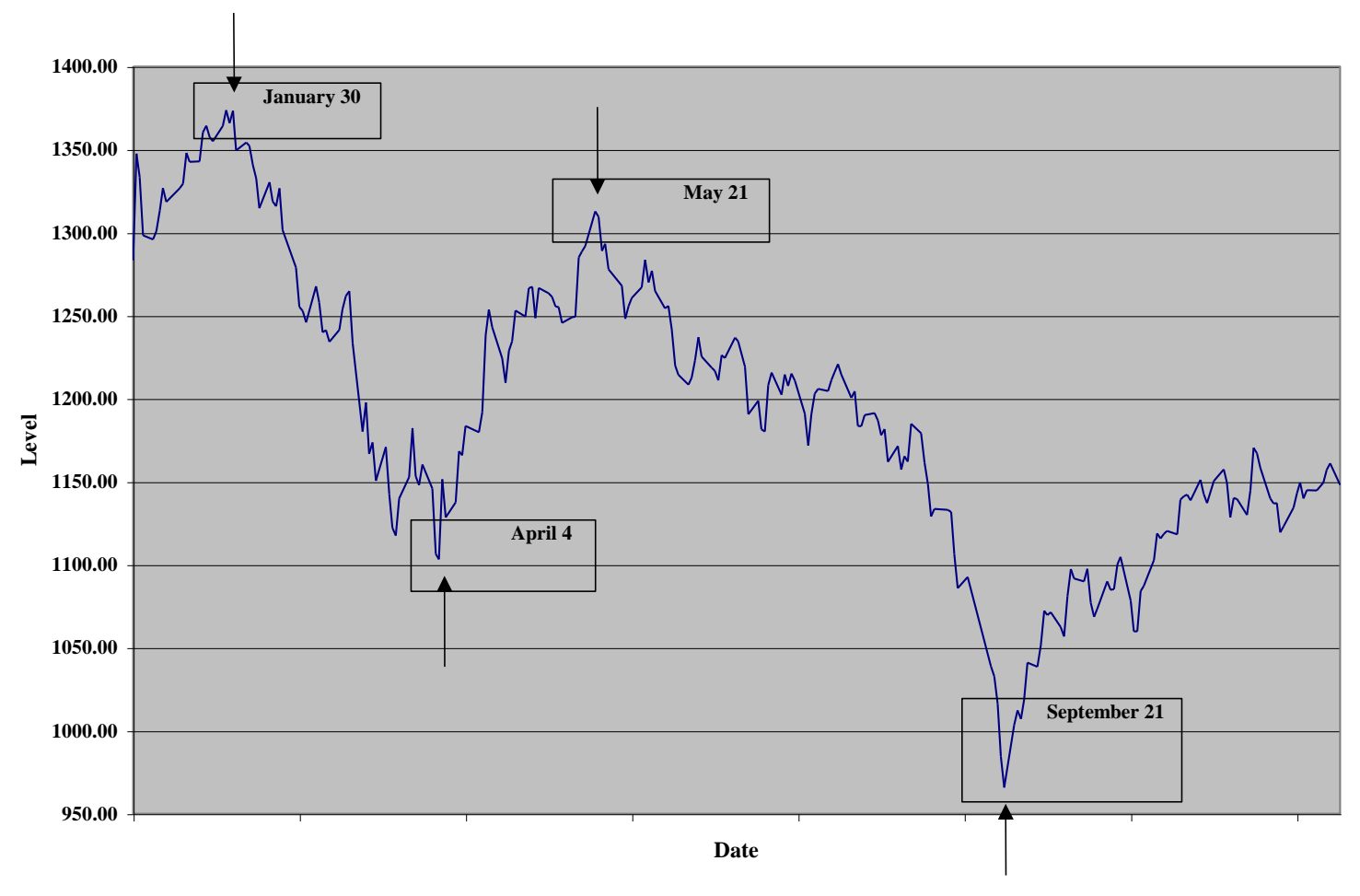


In addition to selecting four local extrema, we also considered the information content of option prices on the two days before and the two days after the critical dates. Table 1 sets out the dates we considered.

Table 1

Dates Before and After Market Shifts

Local maxima January/February May Local minimua April
September

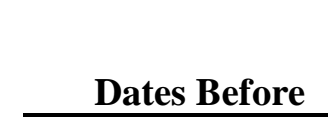

26

17

2

19

29

18

3

20

\begin{tabular}{c|cc}
$\begin{array}{c}\text { Local } \\
\text { Extreme }\end{array}$ & \multicolumn{2}{|c}{ Dates After } \\
\cline { 2 - 2 } $\mathbf{3 0}$ & 31 & 1
\end{tabular}

21

22

23

6

25

According to the theory set out above, one can construct a close approximation to a probability density function of returns on the underlying if one possesses a sufficient number of option prices for a particular maturity at closely spaced strike price intervals. In practice, one faces three main difficulties. The first is that there is the potential for observation error in option prices. Even though observed option prices may meet all of the usual noarbitrage conditions (see the section on Data) there may be variations in prices from one strike price to the next that can introduce material error in a second derivative taken numerically using transactions data. The second is that the strike prices that are traded in the market are sometimes too far apart to permit one to take meaningful numerical second derivatives with respect to strike price. The third is that traded options span a finite range of strike prices. In the absence of traded strike prices corresponding to the tails of the assumed probability density function of returns, one cannot use option prices directly to define the nature of the density function outside of the range of traded strike prices.

To solve these problems, and accordingly, to obtain a smooth, interpretable, and reasonably complete implied probability density function, the methodology must include a procedure to smooth the observed option prices and interpolate between strike prices that are either unobserved ${ }^{4}$ or are too far apart to permit one to determine a meaningful numerical second derivative. In order to define the tails of the probability density function, the methodology must include a procedure for extrapolating beyond the observed strike prices while ensuring that the probability density function integrates to unity. The methodology we use is a variation of the smoothing method proposed by Shimko (1991).

Specifically, our methodology included the following steps:

1. For each of the days specified in Table 1 we obtained prices for call options with the shortest traded maturity in excess of three weeks for as may strike prices as possible. This typically amounted to approximately forty different strike prices.

2. For each observed price we computed Black-Scholes implied volatility. Implied volatility is the volatility parameter that, when used in the Black-Scholes option pricing expression along with the other parameters the pricing algorithm depends on, returns the observed option price.

3. We regressed the implied volatilities from step 2 against orthonormal Hermite polynomials of strike prices in order to obtain an implied volatility function, $\hat{\sigma}(X),^{5}$

$\hat{\sigma}(X) \equiv \alpha+\sum_{i=1}^{5} \beta_{i}\left[\tilde{H}_{i}(X)\right]$ 
where $X=$ strike price, $\hat{\sigma}=$ smoothed implied volatility estimated from the function, and, $\tilde{H}_{j}(X)=j$ th orthonormal Hermite polynomials of $X$.

$$
\tilde{H}_{j}(X) \text { is defined as: }
$$

$\tilde{H}_{-1} \equiv 0$

$\tilde{H}_{0} \equiv \frac{1}{\pi^{1 / 4}}$,

$\tilde{H}_{1}(X) \equiv \frac{\sqrt{2}}{\pi^{1 / 4}} X$

$\tilde{H}_{2}(X) \equiv \frac{1}{\pi^{1 / 4}}\left[\sqrt{2} X^{2}-\frac{1}{2}\right]$

$\tilde{H}_{3}(X) \equiv \frac{1}{\sqrt{6} \pi^{1 / 4}}\left[2^{3 / 2} X^{3}-\left(1+2^{3 / 2}\right) X\right]$,

$\tilde{H}_{j+1}(X) \equiv X \sqrt{\frac{2}{j+1}} \tilde{H}_{j}-\sqrt{\frac{j}{j+1}} \tilde{H}_{j-1}$.

The fitted implied volatility functions typically possessed $R^{2}$ greater than $97 \%$.

4. We used the estimated implied volatility function to generate a smooth and closely spaced set of option prices that we used to take the needed numerical second derivatives of option price with respect to strike price of the form:

$c^{\prime \prime}(X, T, \Delta X) \equiv \frac{[c(X+\Delta X, T)-c(X, T)]-[c(X, T)-c(X-\Delta X, T)]}{(\Delta X)^{2}}$.

Thinking of $X_{i+1}=X+\Delta X, X_{i}=X$, and $X_{i-1}=X-\Delta X$, then:

$P_{i}(X) \approx e^{r(T-t)} c^{\prime \prime}(X, T, \Delta X)$

More specifically, we used the estimated implied volatility function to generate spot estimates of implied volatility. We then used the spot estimates of implied volatility in the Black-Scholes option pricing expression to obtain option price estimates for closely spaced strike prices. Use of the Black-Scholes option pricing expression does not mean that the methodology is based on the assumption that the Black-Scholes model holds. Rather, it arises because we elected to smooth option prices in implied volatility-strike price space and therefore must use the BlackScholes option pricing expression to invert the smoothed implied volatilities back into option price-strike price space.

5. We examined each implied probability density function to ensure it integrated to $e^{-r(T-t)}$, or equivalently, to unity on a future value basis, or more specifically that:

$e^{r(T-t)} \sum_{i} P_{i}\left(X_{i}\right)=1$ 
Because discussions of skewness and kurtosis are generally conducted in the context of the probability density functions of returns, we defined each observation as $x_{i} \equiv \ln \left(X_{i} / F_{0}\right)$ where $F_{0}$ is the futures price at time zero, and calculated the moments of the returns distribution in the following ways:

$$
\begin{aligned}
& \mu_{1}=\sum_{i} x_{i} P_{i}\left(X_{i}\right), \\
& \mu_{2}=\sigma^{2}=\sum_{i}\left(x_{i}-\mu_{1}\right)^{2} P_{i}\left(X_{i}\right) .
\end{aligned}
$$

The skewness of the probability density function of returns is defined as:

$$
\mu_{3}=\sum_{i}\left(\frac{x_{i}-\mu_{1}}{\sigma}\right)^{3} P\left(X_{i}\right) .
$$

The kurtosis of the probability density function of returns is defined as:

$$
\mu_{4}=\sum_{i}\left(\frac{x_{i}-\mu_{1}}{\sigma}\right)^{4} P\left(X_{i}\right)-3
$$

Our expectations concerning the moments of the distribution are as follows:

$\mu_{1}$ : The mean of the distribution if options are priced according to the risk neutral measure should be the riskless interest rate. We expect the mean of the distributions we recover from options prices to reflect this;

$\mu_{2}$ : The stylised facts of returns distributions suggest that volatility following negative moves in the price of the underlying tends to increase and volatility following positive moves tends to decrease. We expect to observe this phenomenon in the distributions we recover; and,

$\mu_{3}$ : Skewness is a measure of the extent to which there is more probability weight on outcomes in the extreme left (negative skewness) or right (positive skewness) tail of a distribution. We expect more negative skewness before a downturn and for this negative skewness to reverse itself after the downturn has occurred. We expect less negative skewness before an upturn and for this to reverse itself after the upturn has occurred. follows:

Our expectations concerning the behaviour of the probability weight in the tails of the distributions are as

a) we expect the market to place relatively more probability weight in the left tail of the probability distribution before a downturn and for this excess weighting to reverse itself after the downturn has occurred; and,

b) we expect the market to place relatively less weight in the left tail of the distribution before an upturn and for this excess weighting to reverse itself after the upturn has occurred.

\section{Data}

This study uses price data for call options written on S\&P 500 index futures, and the prices of the corresponding futures for four selected days in 2001 as well as the two days before and two days after each of the selected days. In addition, we used data for September $10^{\text {th }}, 2001$. We elected to use options on index futures ("index futures options") rather than options written on the index ("index options") because index futures options are traded 
for a broader range of strike prices than is the case for the latter. Contracts are available for strike prices at 5-point intervals for contracts maturing within two months, which are the options of interest in this study. We obtained daily observations of S\&P 500 index futures prices and index futures options prices for the dates indicated in Table 1 from the Financial Post newspaper. We used the mid-point of the bid-ask US Treasury bill quote for the maturity nearest the maturity of the options under consideration as a proxy for the riskless interest rate. ${ }^{6}$ We obtained the quotes from the Wall Street Journal.

The purpose of this study is to examine whether or not short maturity index options contain information concerning the distributions of returns that can be used to predict short-term changes in the level of the index. The study naturally requires limiting the maturity of options it uses to the shorter end of the maturity spectrum. Although this is the case, very short maturity options tend to include relatively little information concerning returns distributions. We therefore arbitrarily elected to use the shortest maturity available to us on any given day provided that the maturity exceeded three weeks. In practice, this means using options with three to four weeks to maturity in some cases and options with three to seven weeks to maturity in the rest of the cases. following: ${ }^{7}$

We excluded option prices that imply arbitrage opportunities. More specifically, we excluded the

a) options with prices less than intrinsic value;

b) options with prices less than the price of an otherwise identical option with a higher strike price;

c) for pairs of otherwise identical call option contracts, cases in which the difference in the values exceeded the difference in their strike prices;

d) for three otherwise identical calls with strike prices $X_{3}>X_{2}>X_{1}$, cases in which the value of the middle call exceeded the weighted average of the values of the first and the third calls, where the weights are $\left(X_{3}-X_{2}\right) /\left(X_{3}-X_{1}\right)$ for the first call and $\left(X_{2}-X_{1}\right) /\left(X_{3}-X_{1}\right)$ for the third call. In other words, violation of the proposition,

$c\left(X_{2}\right) \leq\left(\frac{X_{3}-X_{2}}{X_{3}-X_{1}}\right) c\left(X_{1}\right)+\left(\frac{X_{2}-X_{1}}{X_{3}-X_{1}}\right) c\left(X_{3}\right)$.

If the strike-price intervals in (22) are identical, it can be re-written as,

$c\left(X_{2}\right) \leq\left(\frac{1}{2}\right) c\left(X_{1}\right)+\left(\frac{1}{2}\right) c\left(X_{3}\right)$, or $2 \times c\left(X_{2}\right) \leq c\left(X_{1}\right)+c\left(X_{3}\right)$.

Violation of the proposition in (23) results in a negative value for the numerical second derivative of call option price with respect to strike price, or, equivalently, a negative value in the probability density function.

The options on S\&P 500 index futures are American although we treat them in this study as if they were European. This is equivalent to the assumption that the early exercise premia are negligible. This assumption appears to be reasonable because S\&P 500 index futures do not pay dividends and it is never optimal to exercise an American-style call option before maturity in such cases.

\section{Results}

We used the data described in the preceding section to estimate implied volatility functions for 21 days in calendar 2001. An example of a graph depicting the implied volatility data points and the fitted curves is included in Appendix A. In all cases the $R^{2}$ values in the estimations of the implied volatility functions exceeded $97 \%$. In 18 of the 21 cases examined the $R^{2}$ values exceeded $99 \%$. Appendix B sets out an example of a returns probability 
density functions that was implied by the option prices we observed for a particular day in the study. We include for reference a graph of a normal density function with the mean and volatility parameters set equal to those of the implied density function for the day. The results for the mean of the distribution are set out in Table 2. Further properties of the implied density functions are summarized in Table 3.

Table 2

Short Term Interest Rates

\begin{tabular}{ccccccccc} 
& \multicolumn{2}{c}{ January } & \multicolumn{2}{c}{ April } & \multicolumn{2}{c}{ May } & \multicolumn{2}{c}{ September } \\
Days & Riskless & Actual & Riskless & Actual & Riskless & Actual & Riskless & Actual \\
$\mathbf{- 1 1}$ & - & & - & & - & & $3.360 \%$ & $1.827 \%$ \\
$\mathbf{- 2}$ & $5.010 \%$ & $-2.752 \%$ & $4.750 \%$ & $5.079 \%$ & $3.360 \%$ & $-2.148 \%$ & $2.150 \%$ & $1.853 \%$ \\
$\mathbf{- 1}$ & $4.960 \%$ & $-3.698 \%$ & $4.840 \%$ & $4.397 \%$ & $3.370 \%$ & $-1.897 \%$ & $1.970 \%$ & $1.724 \%$ \\
$\mathbf{0}$ & $4.900 \%$ & $-3.828 \%$ & $4.840 \%$ & $6.212 \%$ & $3.420 \%$ & $-3.723 \%$ & $2.095 \%$ & $1.933 \%$ \\
$\mathbf{1}$ & $4.920 \%$ & $-4.032 \%$ & $4.870 \%$ & $-0.926 \%$ & $3.390 \%$ & $-3.473 \%$ & $2.375 \%$ & $2.065 \%$ \\
$\mathbf{2}$ & $4.610 \%$ & $-5.587 \%$ & $4.700 \%$ & $1.123 \%$ & $3.460 \%$ & $-2.147 \%$ & $2.495 \%$ & $2.126 \%$
\end{tabular}

Perhaps most noteworthy among our findings is the fluctuating behaviour of the mean. Table 2 presents a comparison of the realised means and the riskless interest rates corresponding to the maturity of the options in question. Our expectation was that the mean would track the riskless rate of return. This expectation was grounded in the maintained hypothesis that options are priced under the risk-neutral measure. As it turns out, the means were consistently negative before a downturn and consistently positive before an upturn. In a qualitative sense, the means before upturns were similar to the riskless rate of return.

As can be seen from Table 3, results for volatility were mixed. For the January and May downturns and the April upturn there was little evidence that volatility changed on the happening of the event. For the September upturn, volatility appears to have declined markedly.

Results for skewness appear to be reactive rather than predictive of market moves. For the January downturn skewness increased after the event. It appears that rather than anticipating the event, the market responded to it with an increased "crash fear". For the April upswing, the market appears to have been reactive once again. The April 3, 2001 observation at -2.36 may have been an outlier. In any event, the April 2, 2001 observation was -1 , somewhat less than the observations of -1.15 and -1.07 after the event. For the May event, the market again appears be reactive with crash fears increasing after the downturn. The results for the September event are somewhat inconsistent with crash fears increasing substantially after the upturn following September 21.

We used the implied density functions to estimate the tail probabilities in the implied distributions. Arguably, the tail probabilities reflect the likelihood of extreme moves in the underlying. In one case we considered moves one standard deviation from the mean, and in the second case 1.28 standard deviations form the mean. In the latter case, this corresponds to $10 \%$ probability weight in the tails of the unit normal density function.

For the January event the distributions reflected more weight in the left tail after the event once again suggesting that options prices are reactive rather than predictive of a market shift. For the April upswing, left tail probabilities declined somewhat. For the May downturn, the market reacted much as it did for the April upswing suggesting that there is little to be gained by attempting to predict market moves through this metric. Similarly for the September upswing the market sentiment appeared somewhat less that unequivocal. 
Table 3

Properties of the Implied

Probability Density Functions

\begin{tabular}{|c|c|c|c|c|c|c|c|c|c|}
\hline \multirow{3}{*}{\multicolumn{2}{|c|}{$\begin{array}{c}\text { Days to } \\
\text { Maturity }\end{array}$}} & \multicolumn{3}{|c|}{ Annualized } & \multirow[b]{2}{*}{ Skewness } & \multirow{2}{*}{$\begin{array}{c}\text { Excess } \\
\text { Kurtosis }\end{array}$} & \multicolumn{3}{|c|}{ Probability Weight } \\
\hline & & Mean & Median & Std. Dev. & & & Left tail & Right tail & Ratio \\
\hline & & \multicolumn{8}{|c|}{ Panel A - Downturn } \\
\hline 26-Jan-01 & 15 & $-2.75 \%$ & $7.50 \%$ & $22.11 \%$ & -1.68 & 8.82 & $44.9 \%$ & $55.3 \%$ & 0.81 \\
\hline 29-Jan-01 & 14 & $-3.70 \%$ & $7.00 \%$ & $22.53 \%$ & -1.78 & 10.09 & $45.4 \%$ & $54.8 \%$ & 0.83 \\
\hline 30-Jan-01 & 13 & $-3.83 \%$ & $7.49 \%$ & $22.49 \%$ & -1.81 & 10.67 & $45.4 \%$ & $54.8 \%$ & 0.83 \\
\hline 31-Jan-01 & 12 & $-4.03 \%$ & $8.37 \%$ & $22.56 \%$ & -1.99 & 12.24 & $45.0 \%$ & $55.1 \%$ & 0.82 \\
\hline 1-Feb-01 & 11 & $-5.59 \%$ & $7.98 \%$ & $21.88 \%$ & -2.56 & 18.89 & $44.5 \%$ & $55.8 \%$ & 0.80 \\
\hline \multicolumn{10}{|c|}{ Panel B - Upswing } \\
\hline 2-Apr-01 & 14 & $5.08 \%$ & $11.39 \%$ & $30.24 \%$ & -1.00 & 3.27 & $45.3 \%$ & $54.4 \%$ & 0.83 \\
\hline 3-Apr-01 & 13 & $4.40 \%$ & $16.30 \%$ & $37.39 \%$ & -2.36 & 19.80 & $43.5 \%$ & $56.3 \%$ & 0.77 \\
\hline 4-Apr-01 & 12 & $6.21 \%$ & $13.45 \%$ & $34.40 \%$ & -1.07 & 3.83 & $45.3 \%$ & $54.4 \%$ & 0.83 \\
\hline 5-Apr-01 & 11 & $-0.93 \%$ & $8.51 \%$ & $30.34 \%$ & -1.15 & 5.38 & $46.0 \%$ & $54.0 \%$ & 0.85 \\
\hline 6-Apr-01 & 10 & $1.12 \%$ & $11.54 \%$ & $32.27 \%$ & -1.07 & 4.48 & $45.7 \%$ & $54.2 \%$ & 0.84 \\
\hline \multicolumn{10}{|c|}{ Panel C - Downturn } \\
\hline 17-May-01 & 21 & $-2.15 \%$ & $5.40 \%$ & $21.64 \%$ & -1.45 & 7.45 & $45.5 \%$ & $54.7 \%$ & 0.83 \\
\hline 18-May-01 & 20 & $-1.90 \%$ & $5.66 \%$ & $20.84 \%$ & -1.52 & 7.75 & $30.3 \%$ & $69.8 \%$ & 0.43 \\
\hline 21-Маy-01 & 19 & $-3.72 \%$ & $4.79 \%$ & $20.94 \%$ & -1.74 & 9.94 & $45.7 \%$ & $54.6 \%$ & 0.84 \\
\hline 22-May-01 & 18 & $-3.47 \%$ & $4.72 \%$ & $21.14 \%$ & -1.74 & 9.98 & $45.3 \%$ & $54.9 \%$ & 0.82 \\
\hline 23-May-01 & 17 & $-2.15 \%$ & $5.47 \%$ & $21.22 \%$ & -1.48 & 7.82 & $31.8 \%$ & $68.4 \%$ & 0.46 \\
\hline \multicolumn{10}{|c|}{$\overline{\text { Panel D - Upswing }}$} \\
\hline $10-$ Sep-01 & 9 & $1.83 \%$ & $11.98 \%$ & $27.88 \%$ & -1.01 & 3.92 & $45.9 \%$ & $54.1 \%$ & 0.85 \\
\hline 19-Sep-01 & 22 & $1.85 \%$ & $17.81 \%$ & $42.91 \%$ & -2.54 & 15.17 & $41.2 \%$ & $58.6 \%$ & 0.70 \\
\hline $20-$ Sep-01 & 21 & $1.72 \%$ & $21.64 \%$ & $47.89 \%$ & -2.30 & 11.87 & $40.8 \%$ & $59.1 \%$ & 0.69 \\
\hline 21-Sep-01 & 20 & $1.93 \%$ & $20.41 \%$ & $46.16 \%$ & -2.13 & 10.54 & $41.3 \%$ & $58.5 \%$ & 0.71 \\
\hline 24-Sep-01 & 19 & $2.07 \%$ & $18.38 \%$ & $40.54 \%$ & -3.05 & 23.11 & $41.2 \%$ & $58.6 \%$ & 0.70 \\
\hline $25-$ Sep-01 & 18 & $2.13 \%$ & $16.46 \%$ & $38.86 \%$ & -3.48 & 30.87 & $41.7 \%$ & $58.1 \%$ & 0.72 \\
\hline
\end{tabular}

While these results to not generally meet with the expectations we set out in the methodology section above, they do not rule out the possibility that the observed properties of returns distributions signal changes in general market trends. Rather, they suggest that the options market does not respond with the level of precision and immediacy that we sought to identify and that is implicit in the research design we used.

Noteworthy within the reported results is the significant increase in the magnitude of the left tail probability versus the right tail probability in the days following the September 11, 2001 tragedy. On September $10^{\text {th }}$ the ratio stood at 1.29 (for a 1.28 standard deviation move) versus 2.25 to 2.42 for the period September $19^{\text {th }}$ to $25^{\text {th }}$. This shift implies significantly different risk management considerations depending on whether one is on the long or short side of the market. 
Table 4

Analysis of Tail Probabilities of the

Implied Probability Density Functions

\begin{tabular}{|c|c|c|c|c|c|c|c|c|}
\hline & \multicolumn{4}{|c|}{ Tail Probability Weight } & \multicolumn{2}{|c|}{ Returns } & \multirow{2}{*}{\multicolumn{2}{|c|}{$\begin{array}{c}\text { Ratios of Tail Probabilities } \\
\text { Left Over Right }\end{array}$}} \\
\hline & \multicolumn{2}{|c|}{ 1.0 SD } & \multicolumn{2}{|c|}{$1.28 \mathrm{SD}$} & \multirow{3}{*}{$\begin{array}{l}\text { Over the } \\
\text { Day Ahead }\end{array}$} & \multirow{3}{*}{$\begin{array}{l}\text { To Option } \\
\text { Maturity }\end{array}$} & & \\
\hline & Left tail & Right tail & Left tail & Right tail & & & 1.0 SD & $1.28 \mathrm{SD}$ \\
\hline Panel A - Dow & nturn & & & & & & & \\
\hline 26-Jan-01 & $11.9 \%$ & $11.7 \%$ & $8.0 \%$ & $5.8 \%$ & $0.68 \%$ & $-4.02 \%$ & 1.02 & 1.38 \\
\hline 29-Jan-01 & $11.7 \%$ & $11.5 \%$ & $7.7 \%$ & $5.9 \%$ & $0.70 \%$ & $-4.70 \%$ & 1.02 & 1.32 \\
\hline 30-Jan-01 & $11.6 \%$ & $11.5 \%$ & $7.8 \%$ & $5.7 \%$ & $-0.56 \%$ & $-5.40 \%$ & 1.02 & 1.35 \\
\hline 31-Jan-01 & $11.6 \%$ & $11.3 \%$ & $7.6 \%$ & $5.5 \%$ & $0.54 \%$ & $-4.84 \%$ & 1.03 & 1.39 \\
\hline 1-Feb-01 & $11.1 \%$ & $10.6 \%$ & $7.1 \%$ & $5.1 \%$ & $-1.76 \%$ & $-5.38 \%$ & 1.05 & 1.41 \\
\hline \multicolumn{9}{|c|}{$\overline{\text { Panel B - Upswing }}$} \\
\hline 2-Apr-01 & $13.3 \%$ & $13.0 \%$ & $9.1 \%$ & $6.8 \%$ & $-3.50 \%$ & $8.13 \%$ & 1.02 & 1.34 \\
\hline 3-Apr-01 & $12.0 \%$ & $10.8 \%$ & $8.1 \%$ & $5.1 \%$ & $-0.29 \%$ & $11.63 \%$ & 1.10 & 1.60 \\
\hline 4-Apr-01 & $13.4 \%$ & $12.8 \%$ & $9.0 \%$ & $6.7 \%$ & $4.28 \%$ & $11.93 \%$ & 1.04 & 1.35 \\
\hline 5-Apr-01 & $12.6 \%$ & $12.7 \%$ & $8.6 \%$ & $6.8 \%$ & $-2.02 \%$ & $7.65 \%$ & 1.00 & 1.26 \\
\hline 6-Apr-01 & $13.2 \%$ & $12.9 \%$ & $8.8 \%$ & $7.1 \%$ & $0.81 \%$ & $9.67 \%$ & 1.02 & 1.24 \\
\hline \multicolumn{9}{|c|}{ Panel C - Downturn } \\
\hline 17-May-01 & $12.0 \%$ & $11.7 \%$ & $8.0 \%$ & $6.2 \%$ & $0.27 \%$ & $-5.93 \%$ & 1.03 & 1.29 \\
\hline 18-May-01 & $12.2 \%$ & $11.9 \%$ & $8.1 \%$ & $6.2 \%$ & $1.60 \%$ & $-6.19 \%$ & 1.02 & 1.30 \\
\hline 21-May-01 & $11.7 \%$ & $11.5 \%$ & $7.6 \%$ & $6.0 \%$ & $-0.26 \%$ & $-7.80 \%$ & 1.01 & 1.27 \\
\hline 22-May-01 & $11.6 \%$ & $11.6 \%$ & $7.7 \%$ & $5.9 \%$ & $-1.56 \%$ & $-7.53 \%$ & 1.00 & 1.30 \\
\hline 23-May-01 & $12.3 \%$ & $12.1 \%$ & $8.1 \%$ & $6.3 \%$ & $0.32 \%$ & $-5.97 \%$ & 1.02 & 1.28 \\
\hline \multicolumn{9}{|c|}{ Panel D - Upswing } \\
\hline 10-Sep-01 & $13.4 \%$ & $13.1 \%$ & $9.1 \%$ & $7.0 \%$ & $-5.05 \%$ & $-1.76 \%$ & 1.02 & 1.29 \\
\hline 19-Sep-01 & $11.2 \%$ & $9.0 \%$ & $7.8 \%$ & $3.3 \%$ & $-3.16 \%$ & $5.49 \%$ & 1.24 & 2.35 \\
\hline 20-Sep-01 & $11.4 \%$ & $9.1 \%$ & $8.1 \%$ & $3.4 \%$ & $-1.92 \%$ & $8.65 \%$ & 1.25 & 2.42 \\
\hline 21-Sep-01 & $11.8 \%$ & $9.7 \%$ & $8.3 \%$ & $3.7 \%$ & $3.82 \%$ & $10.57 \%$ & 1.21 & 2.25 \\
\hline 24-Sep-01 & $10.6 \%$ & $8.4 \%$ & $7.4 \%$ & $3.2 \%$ & $0.88 \%$ & $6.75 \%$ & 1.26 & 2.30 \\
\hline 25-Sep-01 & $10.3 \%$ & $8.2 \%$ & $7.2 \%$ & $3.0 \%$ & $-0.52 \%$ & $5.87 \%$ & 1.25 & 2.37 \\
\hline
\end{tabular}

\section{Summary and Conclusions}

Bates's and Rappoport and White found evidence of crash expectations before the 1987 and 1929 crashes respectively, although the timing of the emergence and dissipation of the crash expectations varied between the two studies. This inconsistency led us to question which pattern might exist in today's markets. In addition, the question arises as to whether or not the evolution of the magnitude of crash fears can be tracked and used to predict changes in market direction for changes other than just negative changes, and for changes that are less dramatic than the 1929, and 1987 crashes.

We examined four market reversals in calendar 2001. Using the Breeden and Litzenberger's State-Claim Pricing Approach (1978) we recovered the probability distributions implied by the prices of call options written against S\&P 500 index futures for the date of each reversal as well as the two days before and after each reversal. We found that there was no significant evidence that the market was shifting probability weight in the recovered probability distributions in anticipation of a market reversal or in response to the occurrence of a reversal. Our most significant finding is that a significant shift in the relative magnitudes of the lower tail versus the upper tail of the recovered probability distributions occurred following the September $11^{\text {th }}$ tragedy. The shift to the left tail persisted even after the market reversal that occurred on September $21^{\text {st }}$. 
Suggestions for Future Research: Limitations of this study suggest several areas of further investigations. Twenty-one days observation of implied probability distributions might not be sufficient to find a general tendency of market expectation. An observation of distributions for a longer period will provide a more accurate and detailed insight concerning the evolution of market expectation. In addition, this study focused on shifts in expectations on the days very close to the reversals in the index. A study that considers a wider time frame around a specific event might be more revealing. Finally, more work needs to be done to allow one to fully understand the motivation for the shift in relative tail probabilities.

\section{Appendices}

Appendix A: Observed \& Fitted Black-Scholes Implied Volatility

January 26, 2001

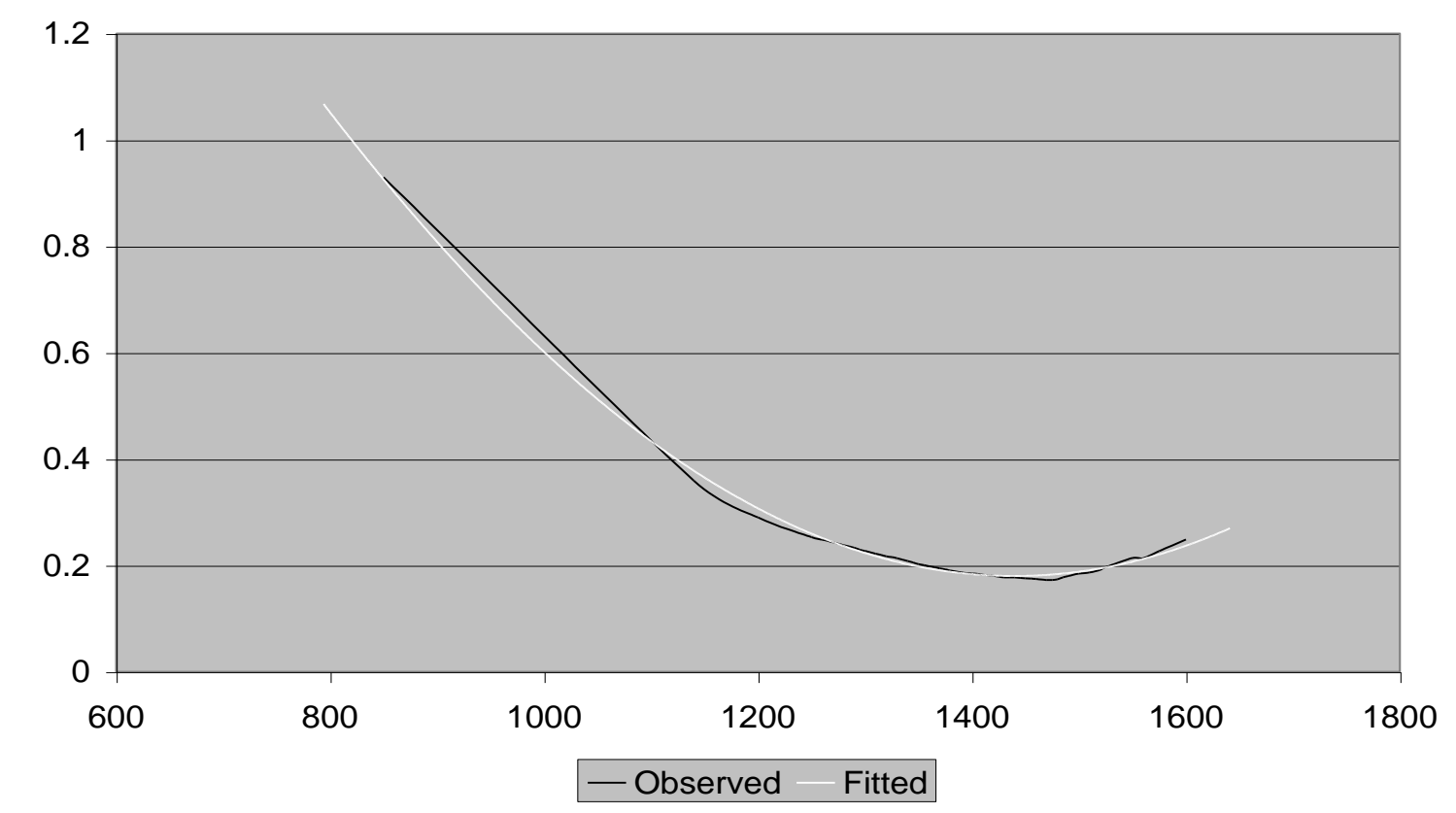

$R^{2}=.997$

\section{Endnotes}

1. $\quad$ c.f. Breeden and Litzenberger (1978).

2. There are other explanations for the volatility smile. For example, the constant elasticity of variance model (Cox, 1975), the leverage models addressed in Geske (1979) and Rubinstein (1983), jump-diffusion models (Merton, 1976), and stochastic volatility models (Heston, 1993) can all exhibit volatility smiles that derive from the fact that the stochastic process assumptions in these models lead to density functions of returns that deviate from normal.

3. In a similar study currently underway the authors are examining more individual events.

4. For example, if traded strike prices are five index points apart, it is possible for an absence of transaction prices to occur such that the difference between observed traded strike prices is 10, 15 or more index points apart.

5. c.f. Press, et al, (1995), or Rice (1964).

6. Neave and Ross (2001) report that different choices of interest rate have very little impact of estimated value of primitive securities, and argue that the particular choice of interest rate is not crucial.

7. c.f. Cox and Rubinstein (1985). 


\section{Appendix B: Implied Probability Distribution}

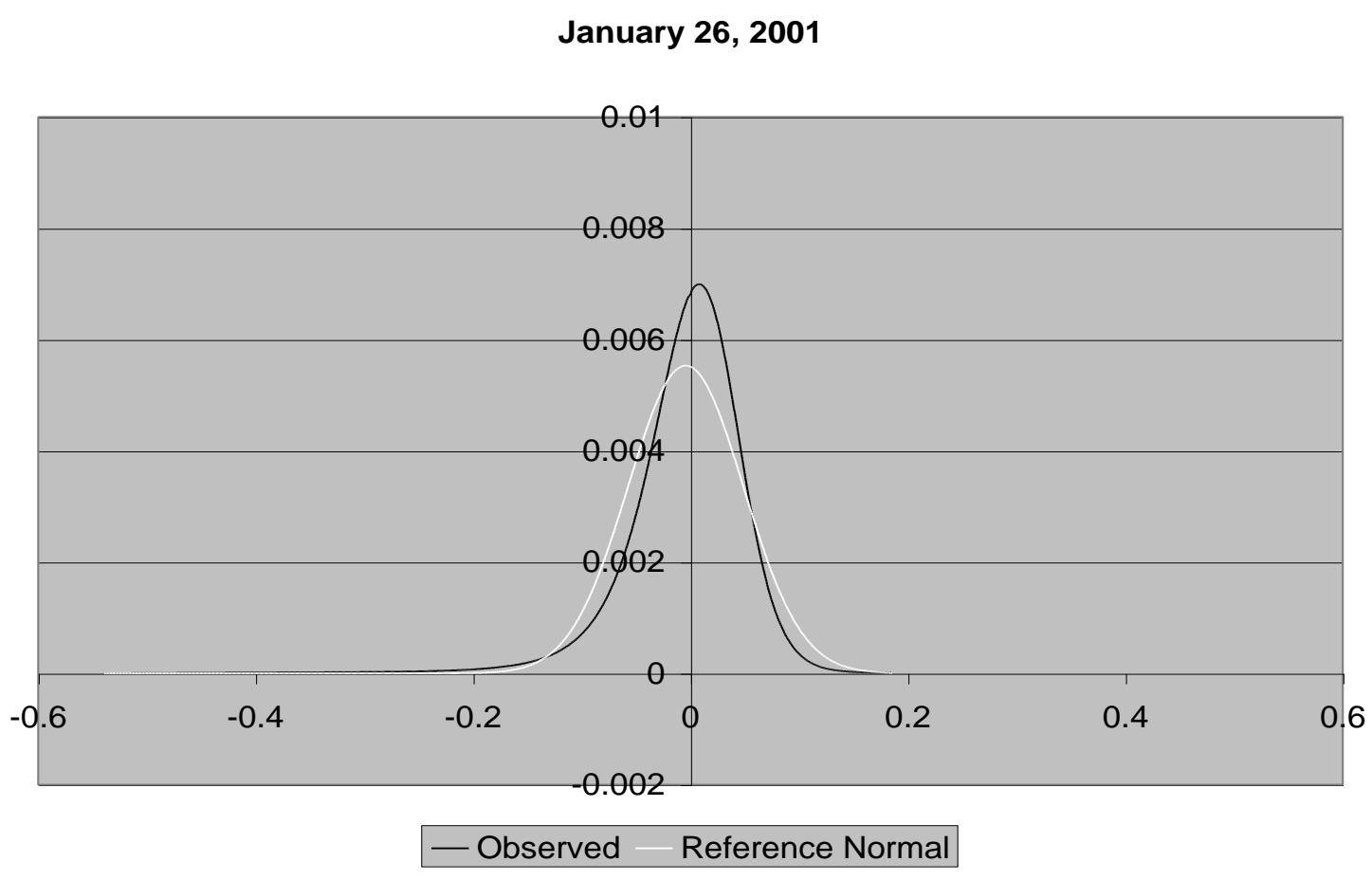

Skewness $=-1.68$

\section{References}

1. Bates, David S., "The Crash of "87: Was It Expected? The Evidence from Options Markets," Journal of Finance, Vol.46, Issue 3, pp.1009-1044, 1991.

2. Cox, John C., "Notes on Option Pricing 1: Constant Elasticity of Variance Diffusions," unpublished manuscript, Stanford University, 1975.

3. Breeden, Douglas and Robert Litzenberger, "Prices of State Contingent Claims Implicit in Option Prices," Journal of Business, Vol.51, Issue 4, pp.621-651, 1978.

4. Cox, John and Mark Rubinstein, Options Markets, Prentice Hall, Englewood Cliffs, New Jersey, 1985.

5. $\quad$ Geske, R., "The Valuation of Compound Options,” Journal of Financial Economics, Vol.7, Issue 1, pp.63-81, 1979.

6. Heston, Steven L., "A Closed-Form Solution for Options with Stochastic Volatility with Application to Bond and Currency Options," Review of Financial Studies, Vol.6, No.2, pp.327-343, 1993.

7. Hull, John, Options, Futures, \& Other Derivatives, Forth Edition, Prentice Hall, Upper Saddle River, New Jersey, 2000.

8. Merton, R. C., "Option Pricing When Underlying Stock Returns are Discontinuous," Journal of Financial Economics, Vol.3, Issue 1-2, pp.125-44, 1976.

9. Neave, Edwin H. and Michael N. Ross, "Claim-Based Asset Pricing: Theory and Application," Administrative Sciences Association of Canada 2001 Proceedings, 2001.

10. Press, William H, Saul A. Teukolsky, William T. Vetterling, and Brian P. Flannery, Numerical Recipes $C$ - The Art of Scientific Computing, Cambridge University Press, Cambridge; New York, 1995.

11. Rappoport, Peter and Eugine N. White, "Was the Crash of 1929 Expected?," The American Economic Review, Vol.84, Issue 1, pp.271-281, 1994.

12. Rice, J. R., The Approximation of Functions, Volumes 1 and 2, Addison-Wesley Publishing Company, Inc., Reading, Massachusetts, 1964.

13. Rubinstein, Mark, "Displaced Diffusion Option Pricing," Journal of Finance, Vol. 38, Issue 1, pp.213-217, 1983.

14. Shimko, David, "Beyond Implied Volatility: Probability Distributions and Hedge Ratios Implied by Option Prices," Working Paper, USC, 1991. 